\title{
PENGARUH METODE KONTRASEPSI ,LAMA PENGGUNAAN KONTRASEPSI TERHADAP KEJADIAN HIPERTENSI PADA IBU PASANGAN USIA SUBUR DIPUSKESMAS PULO BRAYAN TAHUN 2020
}

\author{
Debora Simamora ${ }^{1}$, Elfalini Warnelis ${ }^{2}$ \\ ${ }^{1,2}$ Universitas Imelda Medan \\ hilbramgavriel@gmail.com,geoffreygopaz@gmail.com
}

\begin{abstract}
Based on data from Puskesmas Pulo Brayan Medan, the number of hypertension sufferers in the last 3 years has increased. In 2018 the number of hypertension sufferers was 378 people, in 2019 there were 384 people, and in 2020 there were 394 people. Of the 394 patients with hypertension, 214 were women of PUS. There are many factors that are thought to be the cause of hypertension in women with PUS, such as the use of contraceptives. The aim of this study was to analyze the effect of duration of use of contraceptives, contraceptive methods, duration of use of contraception, on the incidence of hypertension in women with fertility. This research is an analytical research and is quantitative in nature with a case control design (case control). The research was conducted in the area of Pulo Brayan Health Center. The study population was 8,547 people and the sample was obtained as many as 166 people who were divided into 2 groups, each 83 people. Data analysis used univariate analysis, bivariate analysis with chi-square. The results showed that the duration of use of contraception, the method of contraception, the duration of use of contraception, had an effect on the incidence of hypertension, $p<0.05$. The variable with the greatest influence in this study was the variable body mass index (BMI) which had a value of $\operatorname{Exp}(B)=20.639(95 \% C I=$ 5.850-72.823). It is recommended to the Head of Puskesmas Pulo Brayan Medan to inform PUS mothers who use hormonal contraceptives such as pills and injections to carry out routine blood pressure checks at the puskesmas so that early detection of other complications that can accompany an increase in blood pressure.
\end{abstract}

\section{Keywords: Old contraceptive method, Hypertension, Maternal PUS}

\section{PENDAHULUAN}

Program KB yang

berkesinambungan akan mampu menahan laju penduduk. Tetapi saat ini di Indonesia, laju pertumbuhan penduduk pada tahun 2016 sebesar $1,49 \%$ atau sekitar 4.000.000 per tahun. Dengan jumlah laju pertumbuhan sebanyak itu, rata-rata wanita subur melahirkan 2,6 anak, sedangkan targetnya bahwa rata-rata wanita melahirkan 2,1 anak. Hal tersebut dapat mengganggu kesehatan reproduksi wanita dan dapat berpengaruh terhadap angka kematian ibu (BKKN, 2016). Berbagai jenis alat kontrasepsi diperkenalkan pemerintah untuk mengatur jarak kehamilan dan kelahiran baik yang hormonal maupun non hormonal. Alat kontrasepsi 
hormonal seperti pil, suntik, dan implan, sedangkan alat kontrasepsi non hormonal yaitu AKDR, kondom, MOW, MOP, metode sederhana/vaginal atau spermisida. Kedua jenis alat kontrasepsi tersebut mempunyai keuntungan maupun kerugian atau efek samping masing-masing yang harus diketahui oleh calon akseptor (Hartanto, 2014). Salah satu efek samping penggunaan alat kontrasepsi yaitu hipertensi dan menjadi bahasan dalam penelitian ini.

Dalam pemilihan metode kontrasepsi, wanita perlu mempertimbangkan berbagai faktor, mulai dari status kesehatan dan efek samping yang akan timbul setelah lama penggunaan (Suratun, 2013). Kekhawatiran utama pemakaian metode kontrasepsi hormonal adalah peningkatan risiko penyakit sistem kardiovaskuler, terutama keluhan kesehatan terhadap tekanan darah yang meninggi atau hipertensi (Saifuddin, 2014).

Berdasarkan hasil Riset Kesehatan Dasar (Riskesdas) 2007, hipertensi merupakan penyebab kematian nomor tiga $(6,8 \%)$ di
Indonesia setelah stroke $(15,4 \%)$ dan penyakit tuberkulosis. Prevalensi hipertensi pada umur 18 tahun ke atas berdasarkan hasil pengukuran sebesar $31,7 \%$, pada perempuan sebesar 31,9\% dan laki-laki 31,3\%. Hasil Riskesdas tahun 2013, menunjukkan adanya penurunan prevalensi hipertensi menjadi 25,8\%, perempuan $28,8 \%$ dan laki-laki $22,8 \%$. Hipertensi pada perempuan cenderung lebih tinggi dibanding laki-laki (Kemenkes RI, 2013).

Hasil analisa data Riskesdas 2013 menunjukkan bahwa jumlah akseptor KB yang menderita hipertensi sebanyak 25,9\% terutama pada pemakaian KB hormonal. Hasil statistik ada pengaruh penggunaan kontrasepsi terhadap lebih tingginya risiko kejadian hipertensi dini pada perempuan memasuki usia 35 tahun dibandingkan lelaki. Analisa ini menempatkan perempuan dan lelaki dalam variabel yang sama untuk mengetahui sejauh mana kontribusi penggunaan kontrasepsi mempengaruhi risiko kejadian hipertensi. Hasil analisa tersebut membuktikan secara statistik melalui penggunaan kontrasepsi hormonal, perempuan dihadapkan pada faktor 
risiko hipertensi lebih tinggi dibandingkan lelaki (Kemenkes RI, 2013). Berdasarkan data tahun 2020, bahwa dari 394 penderita hipertensi tersebut, sebanyak 214 orang adalah ibu PUS, dan menggunakan alat kontrasepsi baik hormonal maupun nonhormonal. Proporsi penderita hipertensi pada ibu PUS sebesar $64,8 \%$.

\section{METODE}

Penelitian ini merupakan penelitian analitik dan bersifat kuantitatif dengan rancangan kasus kontrol (case control). Penelitian dilakuakn di wilayah Kerja Puskesmas Pulo Brayan. Waktu penelitian dilaksanakan dari bulan Maret - November 2019. Populasi dalam penelitian ini adalah seluruh ibu PUS yang menggunakan alat kontrasepsi sebanyak 8.547 orang. Sampel yg digunakan yaitu sebanyak 166 orang, 83 orang untuk sampel kelompok kasus dan 83 orang untuk sampel kelompok kontrol. Teknik penarikan sampel dalam penelitian ini adalah menggunakan teknik probability sampling, Penentuan atau penarikan sampel diambil dari setiap kelipatan
Berdasarkan uraian di atas peneliti tertarik untuk melakukan penelitian dengan judul: Pengaruh Metode Kontrasepsi, Lama Penggunaan Kontrasepsi, Metode Kontrasepsi terhadap Kejadian Hipertensi Pada Ibu PUS di Wilayah Puskesmas Pulo Brayan Tahun 2020.

interval yang disesuaikan dengan jumlah datai PUS. Adapun kriteria inklusi kelompok kasus adalah PUS yang menderita hipertensi pada saat pemeriksaan dan menggunakan alat kontrasepsi >1 tahun. Kriteria inklusi kelompok kontrol adalah PUS yang tidak menderita hipertensi, menggunakan alat kontrasepsi >1 tahun, dan siklus haidnya teratur. Kriteria eksklusi kelompok kasus dan kontrol adalah PUS memiliki riwayat penyakit hipertensi sebelum penggunaan alat kontrasepsi. memiliki penyakit yang dapat menyertai hipertensi seperti penyakit jantung/ginjal, dan penderita hipertensi yang juga mendapatkan pengobatan. Metode pengumpulan data mengunkan data 
primer dan data sekunder. Analisis data dalam penelitian ini adalah uji uji regresi linier ganda.

\section{HASIL DAN PEMBAHASAN}

1. Karakteristik Responden

Berdasarkan jumlah anak, pada kelompok kasus mayoritas responden mempunyai anak 2 orang sebanyak 35 orang $(42,2 \%)$, minoritas mempunyai anak 4 orang sebanyak 5 orang $(6,0 \%)$. Pada kelompok kontrol mayoritas responden juga mempunyai anak 2 orang sebanyak 34 orang $(41,0 \%)$, minoritas mempunyai anak 4 orang sebanyak 7 orang $(8,4 \%)$. Penghasilan per bulan responden didasarkan pada Upah Minimum Provinsi (UMP) Sumatera Utara tahun 2017 sebesar Rp. 2.528.815.-. Pada kelompok kasus mayoritas responden dengan pendapatan $>\mathrm{Rp}$. 2.528.815.- sebanyak 50 orang (60,2\%), minoritas dengan pendapatan < Rp. 2.528.815.sebanyak 33 orang $(39,8 \%)$. Pada kelompok kontrol mayoritas responden dengan pendapatan $>\mathrm{Rp}$. 2.528.815.- sebanyak 55 orang (66,3\%), minoritas dengan pendapatan < Rp. 2.528.815.sebanyak 28 orang $(33,7 \%)$. Hasil tersebut dapat dilihat pada tabel 1 berikut ini.

\section{Tabel.1 Distribusi Frekuensi Karakteristik Responden}

\begin{tabular}{lcccc}
\hline \multirow{2}{*}{ Karakteristik } & \multicolumn{4}{c}{ Kejadian Hipertensi } \\
\cline { 2 - 5 } & \multicolumn{2}{c}{ Hipertensi } & \multicolumn{2}{c}{$\begin{array}{c}\text { Tidak Hipertensi } \\
\text { (Normal) }\end{array}$} \\
\cline { 2 - 6 } & $\mathbf{F}$ & $\mathbf{9}$ & $\mathbf{f}$ & $\mathbf{\%}$ \\
\hline Umur : & 3 & 3,6 & 2 & 2,4 \\
< 20 Tahun & 32 & 38,6 & 55 & 66,3 \\
20-35 Tahun & 48 & 57,8 & 26 & 31,3 \\
> 35 Tahun & $\mathbf{8 3}$ & $\mathbf{1 0 0}$ & $\mathbf{8 3}$ & $\mathbf{1 0 0}$ \\
\hline \multicolumn{1}{c}{ Jumlah } & & & & \\
\hline Pendidikan: & 3 & 3,6 & 3 & 3,6 \\
Dasar (SD dan SMP) & 49 & 59,0 & 52 & 62,7 \\
Menengah (SMA) & 31 & 37,3 & 28 & 33,7 \\
Tinggi (Perg.Tinggi) & $\mathbf{8 3}$ & $\mathbf{1 0 0}$ & $\mathbf{8 3}$ & $\mathbf{1 0 0}$ \\
\hline \multicolumn{1}{c}{ Jumlah } & & & & \\
\hline Pekerjaan : & 27 & 32,5 & 30 & 36,1 \\
Bekerja & 56 & 67,5 & 53 & 63,9 \\
Tidak Bekerja & $\mathbf{8 3}$ & $\mathbf{1 0 0}$ & $\mathbf{8 3}$ & $\mathbf{1 0 0}$ \\
\hline \multicolumn{1}{c}{ Jumlah } & & & &
\end{tabular}

Jumlah Anak: 


\begin{tabular}{|c|c|c|c|c|}
\hline 1 orang & 16 & 19,3 & 15 & 18,1 \\
\hline 2 orang & 35 & 42,2 & 34 & 41,0 \\
\hline 3 orang & 27 & 32,5 & 27 & 32,5 \\
\hline 4 orang & 5 & 6,0 & 7 & 8,4 \\
\hline Jumlah & 83 & 100 & 83 & 100 \\
\hline \multicolumn{5}{|l|}{ Pekerjaan : } \\
\hline Bekerja & 27 & 32,5 & 30 & 36,1 \\
\hline Tidak Bekerja & 56 & 67,5 & 53 & 63,9 \\
\hline Jumlah & 83 & 100 & 83 & 100 \\
\hline \multicolumn{5}{|l|}{ Jumlah Anak: } \\
\hline 1 orang & 16 & 19,3 & 15 & 18,1 \\
\hline 2 orang & 35 & 42,2 & 34 & 41,0 \\
\hline 3 orang & 27 & 32,5 & 27 & 32,5 \\
\hline 4 orang & 5 & 6,0 & 7 & 8,4 \\
\hline Jumlah & 83 & 100 & 83 & 100 \\
\hline \multicolumn{5}{|l|}{ Penghasilan per bulan: } \\
\hline$<$ Rp. 2.528.815.- & 33 & 39,8 & 28 & 33,7 \\
\hline$>$ Rp. 2.528.815.- & 50 & 60,2 & 55 & 66,3 \\
\hline Jumlah & 83 & 100 & 83 & 100 \\
\hline
\end{tabular}

\section{Metode Kontrasepsi}

Tabel 2. Pengaruh Metode Kontrasepsi Terhadap Kejadian Hipertensi

\begin{tabular}{|c|c|c|c|c|c|}
\hline \multirow{3}{*}{ Metode Kontrasepsi } & \multicolumn{5}{|c|}{ Kejadian Hipertensi } \\
\hline & \multicolumn{3}{|c|}{ Hipertensi } & \multirow{2}{*}{$\frac{\text { (Normal) }}{\%}$} & \multirow[t]{2}{*}{$\mathbf{P}$} \\
\hline & $\mathbf{f}$ & $\%$ & f & & \\
\hline Hormonal & 65 & 78,3 & 11 & 13,3 & $<0,001$ \\
\hline Non hormonal & 18 & 21,7 & 72 & 86,7 & \\
\hline Jumlah & 83 & 100 & 83 & 100 & \\
\hline
\end{tabular}

menunjukkan bahwa pada kelompok kasus responden menggunakan kontrasepsi hormonal sebanyak 65 orang $(78,3 \%)$. Pada kelompok kontrol responden menggunakan kontrasepsi hormonal sebanyak 11 orang $(13,3 \%)$. Hasil pelitian juga menunjukkan adanya pengaruh antara metode kontrasepsi terhadap kejadian hipertensi $(\mathrm{p}=<0,001)$. Hasil konsistensi dengan penelitian-penelitian sebelumnya, pengaruh lama pemakaian kontrasepsi pada terhadap peningkatan tekanan darah pada PUS. Penelitian Lestari (2013) di RW 02 Kelurahan Ngaliyan Semarang bahwa ibu yang lama menggunakan metode kontrasepsi hormonal memiliki peluang 2,954 kali menderita hipertensi dibandingkan dengan ibu yang tidak lama menggunakan metode kontrasepsi 
hormonal, sehingga ada hubungan yang signifikan antara lama penggunaan alat kontrasepsi hormonal terhadap kejadian penyakit hipertensi (Lestari, 2013)

$$
\text { Kontrasepsi yang }
$$

mengandung hormon estrogen akan menimbulkan efek terhadap pembuluh darah berupa hipertrofi arteriol/vasokonstriksi. Selain itu estrogen mempengaruhi sistem Renin Angiotensin-Aldosteron sehingga terjadi ketidak-seimbangan cairan dan elektrolit. Lama penggunaan estrogen juga berpengaruh terhadap terjadinya tekanan darah tinggi. Tekanan darah dapat meningkat sebesar 5 hingga 10 $\mathrm{mmHg}$. Tekanan darah tinggi atau hipertensi yang berlangsung dalam jangka waktu lama merupakan faktor risiko penyakit kardiovaskuler (Sanif, 2013)

\section{Lama Penggunaan Kontrasepsi}

Tabel 3. Pengaruh Lama Penggunaan Kontrasepsi Terhadap Kejadian Hipertensi

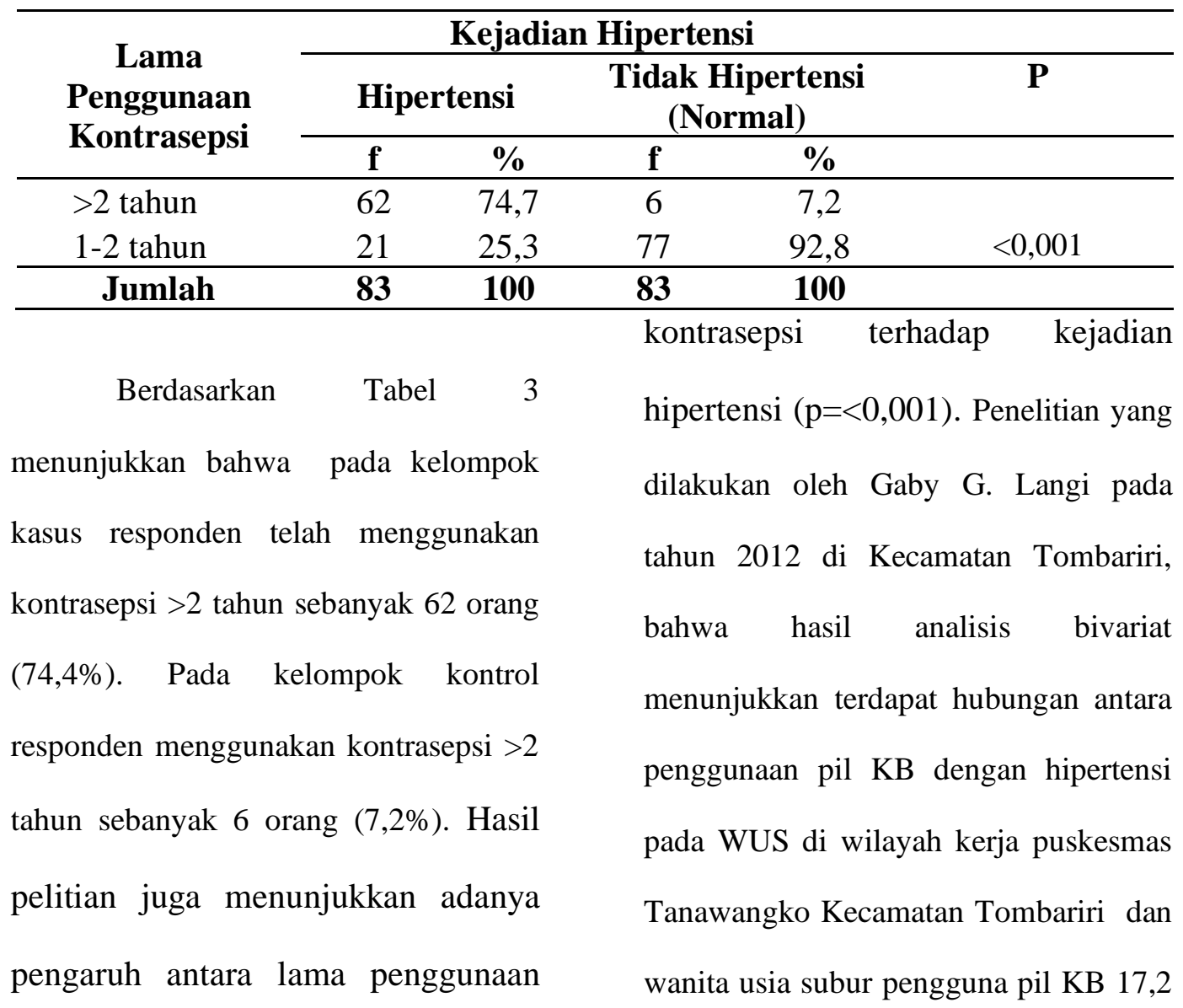


kali berisiko terkena hipertensi dari pada

WUS yang tidak menggunakan pil KB

Hasil penelitian yang dilakukan oleh Anggellya (2017) di Kecamatan Padang Timur menunjukkan hubungan penggunaan kontrasepsi pil terhadap kejadian hipertensi dinyatakan signifikan. Pengguna kontrasepsi pil 3,9 kali berisiko menderita hipertensi dibandingkan bukan pengguna, tetapi pengaruh beberapa faktor risiko hipertensi lain memperlihatkan hubungan tetapi tidak signifikan (Anggellya, 2017)

Berdasarkan hasil penelitian ini menunjukkan bahwa semakin lama menggunakan alat kontrasepsi terutama metode hormonal akan meningkatkan tekanan darah pemakainya. Hal tersebut disebabkan karena hormon estrogen dan progesteron yang semakin lama dan menumpuk dalam tubuh responden dapat meningkatkan retensi elektrolit dalam ginjal, sehingga terjadi peningkatan reabsorbsi natrium dan air yang menyebabkan hipervolemi kemudian curah jantung meningkat dan mengakibatkan peningkatan tekanan darah.

\section{Analisis Bivariat}

Pengaruh Metode Kontrasepsi terhadap Kejadian Hipertensi pada Ibu PUS

Tabel 4. Pengaruh Metode Kontrasepsi terhadap Kejadian Hipertensi

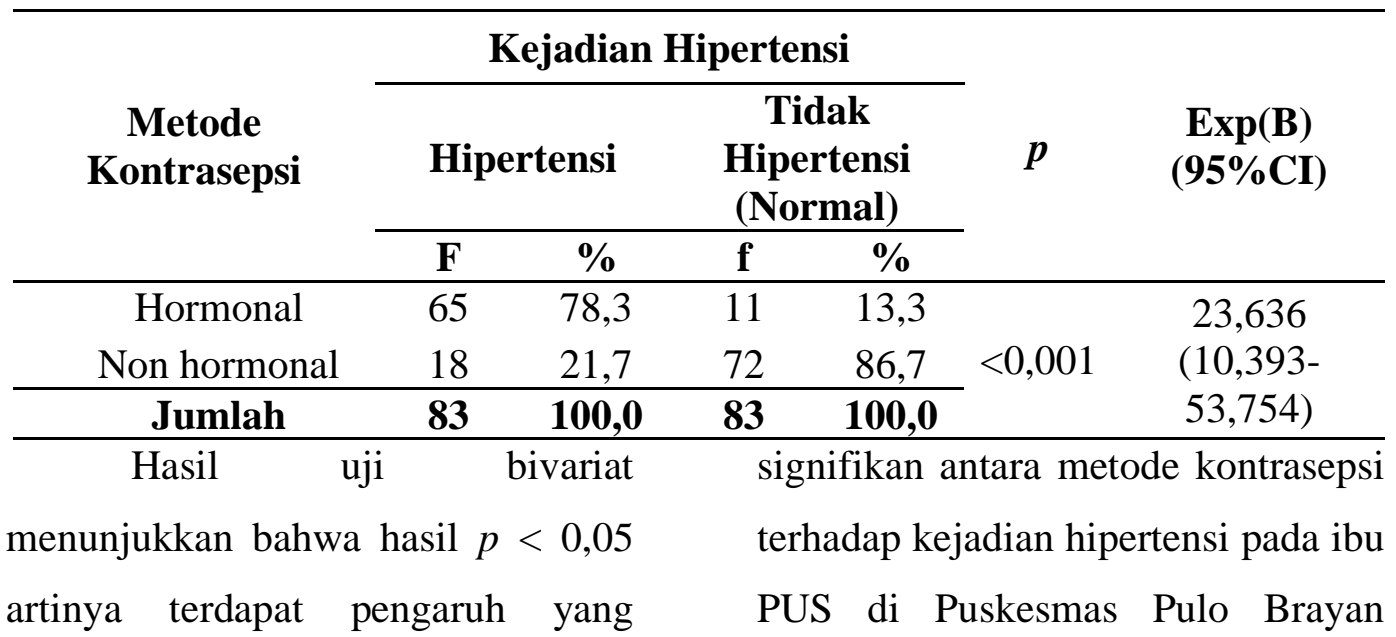


tahun 2020. Hasil pada penelitian ini sama dengan hasil penelitian dari Kawulur (2015) di Wilayah Kerja Puskesmas Tanawongko Kecamatan Tombariri bahwa dari 3 jenis alat kontrasepsi hormonal terbukti bahwa penggunaan alat kontrasepsi hormonal jenis pil yang memberikan pengaruh pada tekanan darah akseptor. Penelitian lainnya oleh Zahidah (2016) di Wilayah Kerja Puskesmas Kedungmundu bahwa jenis alat kontrasepsi hormonal yang digunakan oleh responden menunjukkan sebagian besar responden menggunakan alat kontrasepsi suntik 75\%, yang menggunakan alat kontrasepsi pil $17 \%$ dan kontrasepsi implan 8\%, dengan proporsi tekanan darah tinggi lebih banyak pada responden yang menggunakan alat kontrasepsi pil.

Kemudian pada hasil penelitian Pangaribuan (2015) yang menganalisis Data Riskesdas 2013 menyatakan bahwa jenis KB hormonal pil berisiko 1,4 kali untuk mengalami peningkatan tekanan darah (Pangaribuan, 2013). Berdasarkan hasil penelitian ini bahwa penggunaan metode kontrasepsi yang mengandung hormone berdampak terhadap peningkatan tekanan darah pada ibu WUS yang ada di wilayah Puskesmas Pulo Brayan Medan. Terbukti dari hasil penelitian ini bahwa responden yang menggunakan metode kontrasepsi hormonal mengalami hipertensi dibandingkan dengan responden yang tidak menggunakan metode kontrasepsi hormonal. Responden yang memakai alat kontrasepsi hormonal seperti kontrasepsi suntik dan pil maka dapat menyebabkan terjadinya perubahan tekanan darahnya. 
Pengaruh Lama Penggunaan Kontrasepsi terhadap Kejadian Hipertensi pada Ibu PUS

Tabel 5. Pengaruh Lama Penggunaan Kontrasepsi terhadap Kejadian Hipertensi pada Ibu PUS di Puskesmas Pulo Brayan Tahun 2020

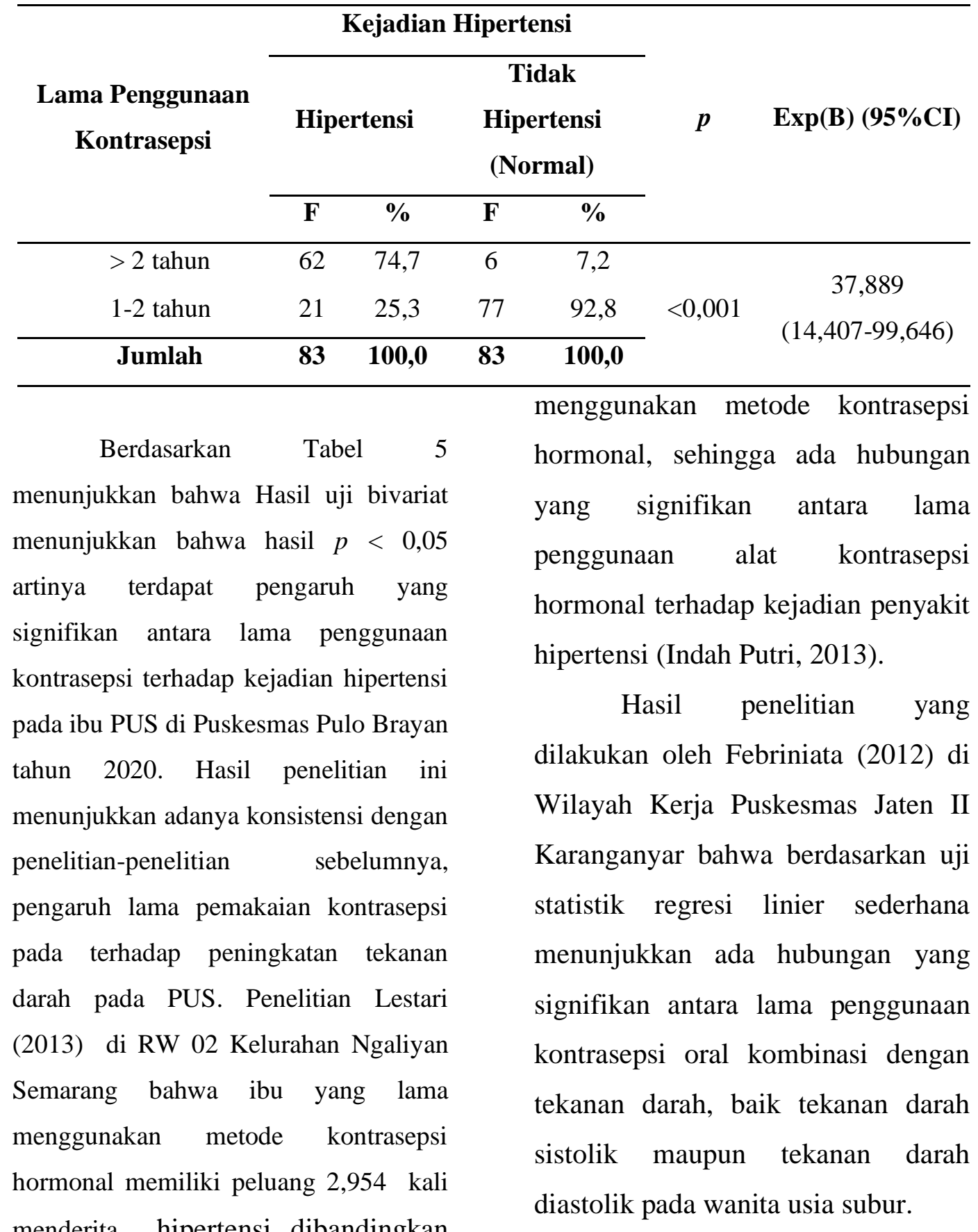




\section{KESIMPULAN DAN SARAN}

Metode kontrasepsi
berhubungan signifikan terhadap
kejadian hipertensi pada ibu PUS di
Puskesmas Pulo Brayan tahun 2020. $p=<0,001<0,05$. Metode kontrasepsi hormonal yang digunakan oleh ibu PUS berhubungan dengan terjadinya peningkatan tekanan darahnya, Lama penggunaan kontrasepsi berhubungan signifikan terhadap kejadian hipertensi pada ibu PUS di Puskesmas Pulo Brayan tahun 2020, $p=<0,001<0,05$. Lamanya menggunakan alat kontrasepsi berhubungan dengan terjadinya peningkatan tekanan darah pada ibu PUS.

Disarankan kepada Kepala Puskesmas Pulo Brayan Medan untuk menginformasikan kepada ibu PUS yang menggunakan alat kontrasepsi hormonal seperti pil dan suntik agar melakukan pemeriksaan tekanan darah secara rutin di puskesmas agar diketahui sejak dini.

\section{DAFTAR PUSTAKA}

Anggellya. (2017). Hubungan antara

Penggunaan Kontrasepsi Pil dengan Kejadian Hipertensi pada Wanita Usia Subur di Kecamatan Padang Timur. Padang.

http://scholar.unand.ac.id/20674

I

BKKN. (2016). Kebijakan Program Kependudukan, Keluarga Berencana, dan Pembangunan Keluarga.

Hartanto. (2014). KB dan Kontrasepsi. Sinar Harapan.

Indah Putri, L. W. E. (2013). Hubungan Antara Lama Penggunaan Metode Kontrasepsi Hormonal Dengan Kejadian Hipertensi. Semarang. Karya Ilmiah STIKES Telogorejo Volume 2, 2. http://ejournal.stikestelogorejo.a c.id/index.php/ilmukeperawatan /article/view/173

Kemenkes RI. (2013). Riset Kesehatan Dasar; RISKESDAS. Pangaribuan. (2013). Hubungan Penggunaan Kontrasepsi Pil Dengan Kejadian Hipertensi Pada Wanita Usia 15-49 Tahun di Indonesia Tahun 2013 (Analisis Data Riskesdas 2013). Media Litbangkes, 25(2).

Saifuddin, A. B. (2014). Buku Panduan Praktis Pelayanan 
Jurnal Maternitas Kebidanan, Vol 6, No. 1, April 2021

ISSN 2599-1841

Kontrasepsi. Penerbit Yayasan

Bina Pustaka.

Sanif. (2013). Hipertensi pada

Wanita. EGC. 